\title{
Thermal analysis at very high temperature
}

by JEGOU C. and BRENIER Y.*

\author{
*CEA - DRN/DER/SERA, CE Cadarache, 13108 Saint-Paul-Lez-Durance, France
}

\begin{abstract}
In the field of severe accident prevention conceming Pressurised Water Reactors, the CEA (French Atomic Energy Commission) is conducting the VULCANO program to analyze the behavior of the melted core of the reactor inside and outside the reactor vessel. The estimated temperatures to be measured are of the order of 1500 to $3000 \mathrm{~K}$. Several technologies are conceivable and one of these is infrared thennography.
\end{abstract}

\section{Introduction}

In the field of severe accident prevention conceming Pressurised Water Reactors, the CEA (French Atomic Energy Commission) is conducting the VULCANO program to analyze the behavior of the melted core of the reactor inside and outside the reactor vessel.

The product of core and structure melting is named corium. The corium is a mixture of uranium dioxide, zirconium dioxide, steel and zirconium and the melting point can vary, due to the appearance of eutectics, from about $1500 \mathrm{~K}$ to $3000 \mathrm{~K}$.

Measuring the temperature inside a corium bath is a considerable challenge. However, a first approach is to estimate the surface thermal field and possibly to demonstrate the appearance of crusts. Several technologies are conceivable and one of these is infrared thermography.

The high level of the temperature entails exceptional difficulties and led to seek for simple but useful means. In this paper, a practical review of tests done to approach the very high temperature field is presented.

\section{Description of the infrared thermography system}

The initial system comprised an AGA $782 \mathrm{SW}$ (3 to $5.6 \mu \mathrm{m}$ wavelength band) camera connected to a computer. The camera was equipped with a GLS filter; two lenses were available: $20^{\circ}$ and $7^{\circ}$.

The system was refurbished by replacing the (failed) Dewar by a Stirling system and replacing the original computer by a versatile CEDIPIADDITIONAL PTR system. This computer allowed to record about 20 minutes of thermal events directly onto the computer 1 Mo disk.

With the GLS filter, one can expect, in best cases, to estimate blackbody temperatures in the order of $1500 \mathrm{~K}$. Over this limit, it is necessary to attenuate the thermal level reaching the camera detector.

\section{First tests at high temperature}

\subsection{Measurement of the surface temperature of a lithium burning bath (fig.1)}

In order to assess the potentialities of the equipment, a series of tests was performed on a lithium buming bath. A quantity of lithium was melted and the liquid lithium poured into a square container in which the lithium ignited spontaneously.

$A$ " $C$ " thermocouple allowed to obtain a reference temperature of $2212^{\circ} \mathrm{C}(2485 \mathrm{~K})$. For the camera, equipped with the $20^{\circ}$ lens, the settings were: Level 940; Range 500; GLS filter; Aperture $1 / 10$.

For post processing analysis the emissivity was set at 0.2 to obtain a faily good thermal image and temperatures of the order of $2000^{\circ} \mathrm{C}$. This approximation can give some information about the temperature field, but the emissivity setting is not very realistic. Results are only indicative.

The colour plates of this article are on pages VII - VIII at the end of the book. 
http://dx.doi.org/10.21611/qirt.1994.020

\subsection{Surface temperature of a graphite crucible at $3013 \mathrm{~K}$ (figs 2 and 3)}

In another test it was attempted to analyze the surface temperature of a small graphite crucible filled with stainless steel and heated by induction $(10 \mathrm{kHz})$ at about $3013 \mathrm{~K}$ (measured with a 0.65 micrometer wavelength "vanishing" filament pyrometer). In this experiment the settings were: Level 988; Range 500; GLS filter; Aperture 1/14.

To obtain a good correspondence between the infrared image and the measured temperature the emissivity had to be adjusted to 0.31 . To protect the camera from the direct radiation of the crucible an attempt was made by using a simple mirror. In this configuration the settings were: Level 74; Range 200; Aperture 1/10. Certainly, with more available time to adjust the parameters of the camera, more conventional settings could have been obtained, but first tests to maintain $3000^{\circ} \mathrm{C}$ in open air induced the staff to hurry!

The apparent temperature with an emissivity of 0.30 was about $700^{\circ} \mathrm{C}$ and to obtain the real temperature of $2940^{\circ} \mathrm{C}$, the computed level had to be adjusted to 2100 , widely above the normal setting of 1000 . Although the method was quite unorthodox, the advantage of this configuration was to have a view under quasi-normal incidence; the isothermal areas were thus more visible. Calibration curves had to be established to achieve a better interpretation of the thermograms.

\section{New tests on graphite and zirconia samples}

\subsection{General points}

To attempt to simulate very high surface temperatures, an oxyacetylene torch was used. Experience showed that the flame of the torch did not perturb the thermal field and allowed to achieve good thermograms at very high temperature. This is due to the low level of the infrared rays emitted in the $3-5.6 \mu \mathrm{m}$ band by the flame of the torch (remember that one can protect

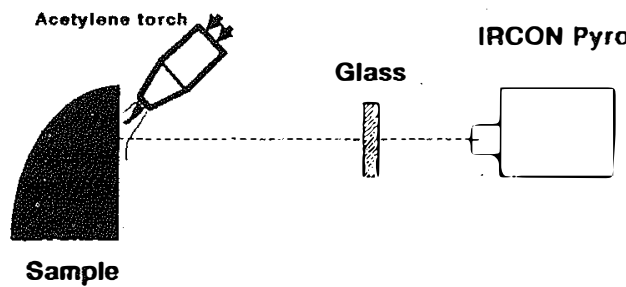
the torch flame in one's hand).

To measure the surface temperature a bicolor infrared pyrometer IRCON working at 0.95 and $1.05 \mu \mathrm{m}$ wavelengths was used. If graphite and zirconia can be considered as gray bodies, the pyrometer gave a reference temperature. Furthermore, due to the relatively high transparency of glass in the $0.95-1.05 \mu \mathrm{m}$ band, the temperature through a glass (or PYREX) window could be measured, provided the "emissivity slope" was adjusted according to the thickness of the window (see Table No1).

\begin{tabular}{|c|c|c|c|c|}
\hline \multirow[t]{2}{*}{ Table No1 } & IRCON 700 & $800^{\circ} \mathrm{C}$ PYROMETER - ACT & $\checkmark$ OF A WINDOW GLAS & \\
\hline & \multicolumn{2}{|c|}{ Measured temperature ${ }^{\circ} \mathrm{C}$} & \multicolumn{2}{|c|}{ Measured temperature ${ }^{\circ} \mathrm{C}$} \\
\hline Glass thickness $\mathrm{mm}$ & $\begin{array}{c}\text { Directly on the graphite } \\
\text { with emissivity slope }=1,0\end{array}$ & $\begin{array}{l}\text { Through the glass with } \\
\text { emissivity slope }=1,0\end{array}$ & $\begin{array}{c}\text { Adjusted emi } \\
\text { siope }\end{array}$ & Reading ${ }^{\circ} \mathrm{C}$ \\
\hline Pyrex & 1042 & 1089 & 1,035 & 1044 \\
\hline Glass & 1044 & 1088 & 1,030 & 1045 \\
\hline 51 & 1044 & 1062 & 1,015 & 1044 \\
\hline 4 & 1045 & 1067 & 1,015 & 1045 \\
\hline 3 & 1046 & 1060 & 1,010 & 1046 \\
\hline 2 & 1045 & 1064 & 1,010 & 1046 \\
\hline
\end{tabular}

To visualize the thermal levels on a surface at very high temperature, the thermal flux reaching the IR camera had to be limited. Several simple ways to achieve this goal were tried:

- The GLS filter of the camera (see Table N² for the transmission curve of the GLS filter) was used; this filter; allowed to measure a blackbody temperature of about $1500 \mathrm{~K}$, 
http://dx.doi.org/10.21611/qirt.1994.020

- A test with a two-millimeter thickness window glass used as a filter; the views were good and the camera without the GLS filter could be used so as to observe temperatures as high as $2000^{\circ} \mathrm{C}$,

- A test with a two-millimeter thickness window glass added to the GLS filter. The attenuation was considerably higher. But, observing the transmission curves of the window glass and those of the GLS filter, it was noted that they were practically complementary (see Table $N^{\circ} 2$ ).

- To simulate the portholes of a mock-up in which a bath of melted UO2 ( $3000 \mathrm{~K})$ is created, the hot surface was observed through a $20 \mathrm{~mm}$-thick PYREX,

- Tests using window glass as reflectors.

Table $\mathrm{N}^{\circ} 2$ TRANSMISSION FACTOR OF 2 MM THICK GLASS (TR $2 \mathrm{~mm}$ ) - GLS AGEMA FILTER AND COMBINED TRANSMISSION VERSUS WAVELENGTH

\begin{tabular}{|c|c|c|c|c|c|c|c|}
\hline Lbd $\mu \mathrm{m}$ & TR2 $2 \mathrm{~mm}$ & FILT GLS & Tr2"F.GLS & Lbd $\mu \mathrm{m}$ & TR2 $2 \mathrm{~mm}$ & FILT GLS & Tr2"F.GLS \\
\hline 3,00 & 0,433 & 0,0000 & $0,00 E+00$ & 4,40 & 0,150 & 0,0083 & $1,25 \mathrm{E}-03$ \\
\hline 3,10 & 0,450 & 0,0000 & $0,00 E+00$ & 4,50 & 0,075 & 0,0083 & $6,23 \mathrm{E}-04$ \\
\hline 3,20 & 0,425 & 0,0000 & $0,00 E+00$ & 4,60 & 0,020 & 0,0083 & $1,66 \mathrm{E}-04$ \\
\hline 3,30 & 0,400 & 0,0000 & $0,00 E+00$ & 4,70 & 0,000 & 0,0430 & $0,00 E+00$ \\
\hline 3,40 & 0,385 & 0,0000 & $0,00 E+00$ & 4,80 & 0,000 & 0,4000 & $0,00 E+00$ \\
\hline 3,50 & 0,375 & 0,0000 & $0,00 E+00$ & 4,90 & 0,0001 & 0,81001 & $0,00 E+00$ \\
\hline 3,601 & 0,383 & 0,0000 & $0,00 E+00$ & 5.00 & 0,000 & 0,8000 & $0,00 E+00$ \\
\hline 3,70 & 0,405 & 0,0000 & $0,00 E+00$ & 5,10 & 0,000 & 0,8000 & $0,00 E+00$ \\
\hline 3,801 & 0,4101 & 0,0000 & $0,00 E+00$ & 5,20 & 0,000 & 0,8450 & $0,00 E+00$ \\
\hline 3,901 & 0,4331 & 0,0000 & $0,00 E+00$ & 5,30 & $0,000 \rrbracket$ & 0,8900 至 & $0,00 E+00$ \\
\hline 4,00 & 0,430 & 0,0083 & $3,57 \mathrm{E}-03$ & 5,40 & 0,000 & 0,8720 & $0,00 E+00$ \\
\hline 4,10 & 0,383 & 0,0083 & $3,18 \mathrm{E}-03$ & 5,50 & 0,000 & 0,8900 & $0,00 E+00$ \\
\hline 4,20 & 0,310 & 0,0083 & 2,57E-О3 & 5,60 & 0,000 & 0,9090 & $0,00 E+00$ \\
\hline 4,30 & 0,275 & 0,0083 & $2,28 \mathrm{E}-03$ & & & & \\
\hline
\end{tabular}

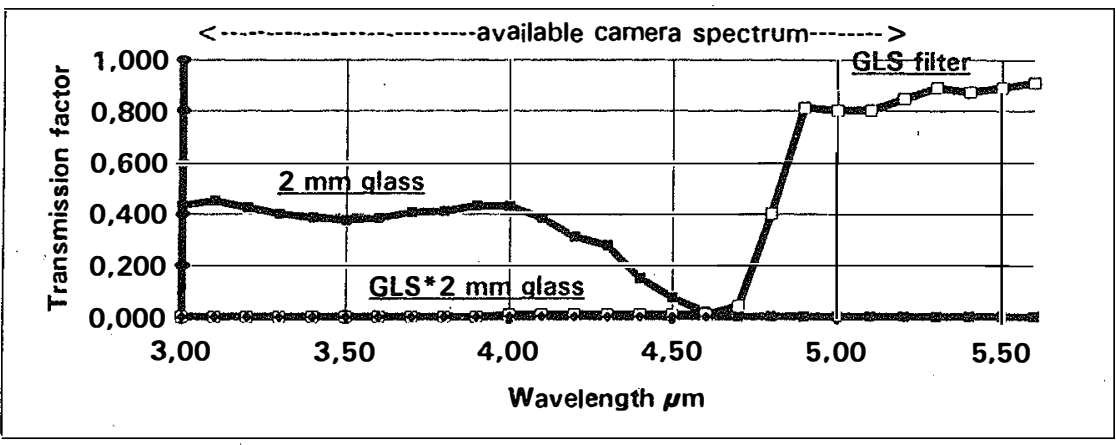

Thermograms were recorded during tests which enable the advantages and the limits of the various configurations to be observed. But, to restitute an accurate thermal map, it is necessary to calibrate the "thermal level" curves for the real configuration with experimental measurements. Temperature measured with the IRCON pyrometer has to be taken as reference temperature.

\subsection{Direct observation of a graphite sample (fig. 4)}

The graphite sample was heated by an oxyacetylene torch flame. The heating mean was the same for all the other tests. The temperature measured with the IRCON pyrometer was $1698^{\circ} \mathrm{C}$ $(1971 \mathrm{~K})$ and the settings of the IR system were: Emissivity 1.0; Lens $7^{\circ}$; Filter GLS; Aperture 1/20; Distance $145 \mathrm{~cm}$; Range 1000; Level 620.

Analysis of the thermogram gives a hot spot temperature of $1429{ }^{\circ} \mathrm{C}(1702 \mathrm{~K})$. A first appreciation indicates an apparent emissivity of 0.55 under the assumption that the graphite can be assumed as being a gray body in the range 0.95 and $1.05 \mu \mathrm{m}$. The estimated value of $e=0.55$ in the $3-5.6 \mu \mathrm{m}$ band is in fair correspondence with the values that can be found in Ref.[1]. 
http://dx.doi.org/10.21611/qirt.1994.020

\subsection{Observation of a graphite sample through a 2-mm thick window glass sheet (fig. 5)}

The temperature measured directly with the IRCON pyrometer was $1670^{\circ} \mathrm{C}(1943 \mathrm{~K})$ and the settings of the IR system were: Emissivity 1.0; Lens $7^{\circ}$; no filter - Aperture 1/20; Distance $170 \mathrm{~cm}$; Range 1000; Level 710

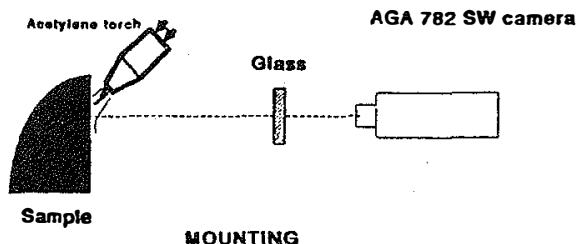

MOUNTING

Analysis of the thermogram gives a hot spot temperature of $824^{\circ} \mathrm{C}(1097 \mathrm{~K})$. A first appreciation indicates an apparent transmission factor of 0.10 . If a 0.55 emissivity of the graphite is considered, the transmission factor of the glass results of the order of $20 \%$. The thermal gradient is clearly visible on the thermogram. In this configuration it was possible to estimate high thermal levels without using a specific camera filter.

\subsection{Observation of a graphite sample through a 2-mm thick window glass sheet using the GLS filter (fig. 6)}

The temperature measured directly with the IRCON pyrometer was $2050^{\circ} \mathrm{C}(2323 \mathrm{~K})$ and the settings of the IR system were: Emissivity 1.0; Lens $7^{\circ}$; Filter GLS; Aperture 1/1.8; Distance 145 cm; Range 20; Level 16.

Analysis of the thermogram gives a hot spot temperature of $37.5^{\circ} \mathrm{C}(310.5 \mathrm{~K})$.

With the same hypothesis as above, a transmission factor of about 0.00032 can be evaluated. Considering a 0.55 emissivity for the graphite, the transmission factor for the $2 \mathrm{~mm}$ glass can be estimated at about 0.00058 if the GLS filter is used. A primary analysis allowed to state that with the GLS filter the transmission factor of a $2 \mathrm{~mm}$ glass sheet is about 290 times less than without the filter!

However, referring to the curves of Table $\mathrm{N}^{\circ} 2$ one can see that the combination of glass and GLS transmission factor drastically attenuates the energy reaching to the camera detector. This can also allow observation of sources at very high temperature and estimation of the thermal gradients.

\subsection{Observation of a graphite sample by reflection with a window glass sheet (fig.7)}

A $8 \mathrm{~mm}$-thick glass sheet was used as a mirror under an incidence of $15^{\circ}$ (the nearer the reflection was to the normal, the less the reflected image was troubled). The temperature measured directly with the IRCON pyrometer was $1595^{\circ} \mathrm{C}(1868 \mathrm{~K})$. The settings of the IR system were: Emissivity 1.0; Lens $7^{\circ}$; no filter; Aperture 1/7.2; Distance $170 \mathrm{~cm}$; Range 500; Level 480.

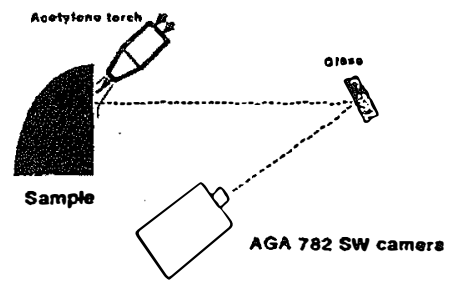

Analysis of the thermogram gives a hot spot temperature of $393^{\circ} \mathrm{C}(666 \mathrm{~K})$. In this configuration, the apparent reflection factor is about 0.016 ; by assuming an emissivity of 0.55 , it can be considered that one reflection strongly attenuates the incident energy so to let pass only about $3 \%$ of this energy. The analysis of the thermal scene could be correctly achieved.

One can notice that, to appreciate the influence of the reflecting surface, it was necessary to know the real surface temperature. It was also necessary to use a very thick sheet to reduce the influence of the secondary reflection on its rear side. 
4.6. Observation of a graphite sample by double reflection with two sheets of window glass (fig. 8)

Two glass sheet were used to attempt to observe a graphite crucible heated from the rear with the oxyacetylene torch. The temperature measured directly with the IRCON pyrometer was $1033^{\circ} \mathrm{C}$ $(1306 \mathrm{~K})$. The settings of the IR system were: Emissivity 1.0; Lens $7^{\circ}$;no filter, Aperture 1/5.1; Distance $200 \mathrm{~cm}$; Range 20; Level 10.

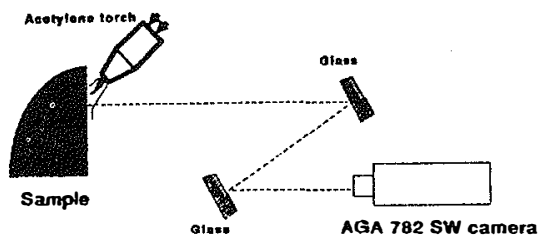

Analysis of the thermogram gives a hot spot temperature of $67.8^{\circ} \mathrm{C}(340.8 \mathrm{~K})$. In this configuration, the apparent reflection factor is about 0.0046 . By assuming an emissivity of 0.55 , it can be considered that the reflection attenuates the incident energy so to let pass only about $0.8 \%$ of this energy. The thermogram is sufficiently contrasted to highlight the isothermal areas.

Although less simple than just one reflection, double reflection strongly attenuates the incident energy.

\subsection{Direct observation of a zirconia sample (fig. 9)}

Here again the zirconia sample was heated by an oxyacetylene torch flame. The temperature measured with the IRCON pyrometer was $1870^{\circ} \mathrm{C}(2143 \mathrm{~K})$. The settings of the IR system were: Emissivity 1.0; Lens $7^{\circ}$; Filter GLS; Aperture 1/20; Distance $145 \mathrm{~cm}$; Range 500; Level 1000.

Analysis of the thermogram gives a hot spot temperature of $1527^{\circ} \mathrm{C}(1800 \mathrm{~K})$. A first appreciation indicates an apparent emissivity of 0.50 under the assumption that the zirconia can be estimated as being a gray body in the 0.95 and $1.05 \mu \mathrm{m}$ range. The estimated value of $e=0.50$ at $2140 \mathrm{~K}$ in the $3-5.6 \mu \mathrm{m}$ band is in fair correspondence with the values reported in Ref.[1] \& [2].

\subsection{Observation of a zirconia sample through a 2-mm thick window glass sheet (fig.10)}

The temperature measured with the IRCON pyrometer was $1888^{\circ} \mathrm{C}(2161 \mathrm{~K})$. The settings of the IR system were: Emissivity 1.0; Lens $7^{\circ}$; no filter; Aperture 1/20; Distance $145 \mathrm{~cm}$; Range 500; Level 954.

Analysis of the thermogram gives a hot spot temperature of $819^{\circ} \mathrm{C}(1092 \mathrm{~K})$. The apparent transmission factor is about 0.065 . If an emissivity of 0.50 for the zirconia is assumed, the transmission factor for the glass can be estimated at about $13 \%$.

The thermal zones are clearly visible on the thermogram. Here again, it was possible to estimate high thermal levels without using a specific camera filter.

\subsection{Direct observation of a zirconia sample through a 2-mm thick window glass sheet using} the GLS filter (fig. 11)

The temperature measured with the IRCON pyrometer was $2229^{\circ} \mathrm{C}(2572 \mathrm{~K})$. The settings of the IR system were: Emissivity 1.0; Lens $7^{\circ}$; Filter GLS; Aperture 1/1.8; Distance $145 \mathrm{~cm}$; Range 20; Level 20.

Analysis of the thermogram gives a hot spot temperature of $51.8^{\circ} \mathrm{C}(324.8 \mathrm{~K})$. In this configuration, the transmission factor could be estimated up to 0.00025 . If 0.5 is assumed as emissivity of zirconia, the transmission factor for the $2 \mathrm{~mm}$ glass is 0.00050 . As in the case of the graphite, the transmission coefficient of the $2 \mathrm{~mm}$ glass is about 260 times less than without the GLS filter, the interpretations are, of course, the same. 
http://dx.doi.org/10.21611/qirt.1994.020

4.10. Observation of a zirconia sample through a 20-mm thick PYREX porthole (fig. 12)

Before this test, an unsuccessful attempt to measure the temperature of a black body heated to $250^{\circ} \mathrm{C}$ through a $20 \mathrm{~mm}$ thickness PYREX porthole was made. A new attempt with very hot zirconia worked out.

The temperature measured with the IRCON pyrometer was $1900^{\circ} \mathrm{C}(2173 \mathrm{~K})$. The settings of the IR system were: Emissivity 1.0; Lens $7^{\circ}$; Filter no filter; Aperture 1/5.1; Distance $145 \mathrm{~cm}$; Range 500; Level 958.

Analysis of the thermogram gives a hot spot temperature of $405^{\circ} \mathrm{C}(678 \mathrm{~K})$. The apparent transmission factor is of the order of 0.0095 , If the zirconia emissivity is considered, the transmission factor for the $20 \mathrm{~mm}$ PYREX porthole could be estimated as being of the order of $2 \%$. This is of great interest to estimate the surface temperature of melted UO2 in the mock-up: the wide Pyrex porthole could be a sufficient filter, and one would not be obliged to replace it with a small brittle sapphire porthole.

\section{Discussion - Conclusions}

All performed tests allow to assert that several simple methods can be used to attenuate the IR radiation of very hot sources in the $3-5.6 \mu \mathrm{m}$ band. Nevertheless, to quantify temperature as much as possible, this latter has to be also measured somewhere by means of a thermocouple or a pyrometer that can give a reference temperature. For example, a bi-color pyrometer working at 0.95 and $1.05 \mu \mathrm{m}$ allows to measure (after correction) a blackbody temperature through glass or PYREX.

For each configuration it would be necessary to calibrate the "thermal level" curves (for each aperture). Temperatures measured with the IRCON pyrometer will have to be taken as reference temperatures ("experimental calibration" of the CEDIP-ADDITIONAL PTR 2 system).Some further difficulties have to be taken into account:

- Estimation of the real emissivity at very high temperature in the 3-5.6 $\mu \mathrm{m}$ band;

- Knowledge of the emissivity slope to determine the black body temperature with the bi-color pyrometer,

- Evolution of the transmission (or reflection) coefficients of filters with the blackbody temperature evolution of the target; the system could be calibrated but, above $1500 \mathrm{~K}$, finding reference sources is not obvious!

The conducted tests were very practical. The objectives were:

- How can temperatures and thermal gradients of very hot surfaces be evaluated?

- Is it possible to find simple methods to achieve this goal?

- What are the difficulties, and what ways are there of solving them?

One may conclude that, to measure very high surface temperatures with an AGA 782 SW camera, it is possible to use:

- An AGEMA GLS filter for maximum black body temperature of $1500 \mathrm{~K}$, by assuming that the absorption spectrum is continuous;

- One window glass sheet ( $2 \mathrm{~mm}$ thickness or other), used as a mirror or a filter (if used mirror it is better a very thick glass to avoid double reflection); in this case it is necessary to measure a reference temperature (thermocouple or pyrometer);

- The double reflection with the same precautions as above;

- The GLS filter and the $2 \mathrm{~mm}$ thickness glass for extreme conditions such as a melted ceramics bath.

\section{REFERENCES}

[1] SALA (A.), Radiant Properties of Materials, Elsevier.

[2] TOULOUKIAN (Y:S:), Thermophysical Properties of High temperature Solid Materials, MacMillan 